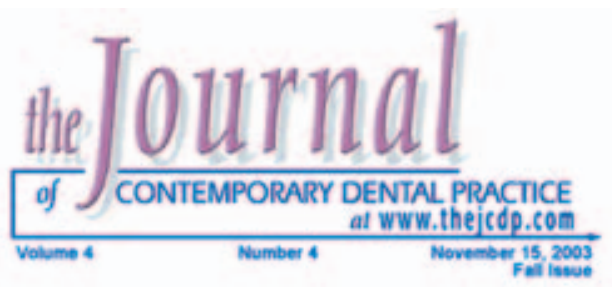

\title{
Broken Appointment Behavior in a Dental School Enviornment
}

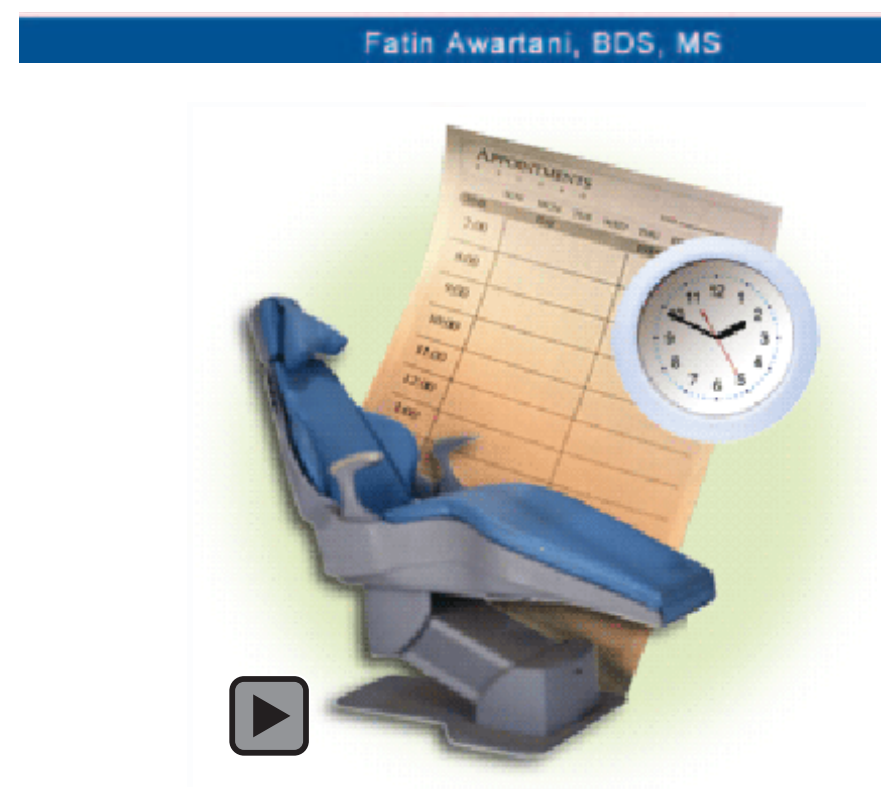

\section{Abstract}

The present study was designed to determine the prevalence of broken appointments of female and male patients scheduled for third, fourth, and fifth year dental students. Data was obtained from computers used for patient scheduling at two campuses of the dental college. The proportion of broken appointments at these facilities was computed using the $\mathrm{X}^{2}$-test to determine a difference between males and females. Results showed that male patients (14.9\%) had a higher proportion of broken appointments than female patients $(12.4 \%)$. Such differences among gender was statistically significant $(\mathrm{p}=4.218)$.

The highest percentage of broken appointments was during December of 2001. Thirty four percent of these broken appointments were in the Restorative Clinic at the Darraiyah Campus (DUC) serving primarily male patients and $24 \%$ in the Removable Partial Denture Clinic at the Malaz Campus (MUC) serving only female patients.

It was concluded the percentage of broken appointment $s$ is considered to be unacceptable because of the negative impact on student learning and, ultimately, their academic progress.

Keywords: Dental appointments, dental appointment failure, failed dental appointments, broken dental appointments

Citation: Awartani F. Broken Appointment Behavior in a Dental School Environment. J Contemp Dent Pract 2003 November;(4)4:100-107.

\author{
(c) Seer Publishing
}


Introduction

King Saud University, Dental

College in Riyadh City was established in 1975. It has two branches: (1) the Malaz Campus (MUC) located in the center of the city that primarily serves female students and patients and (2) the Darraiyah Campus (DUC) located in the northern part of the city that primarily serves male students and patients.

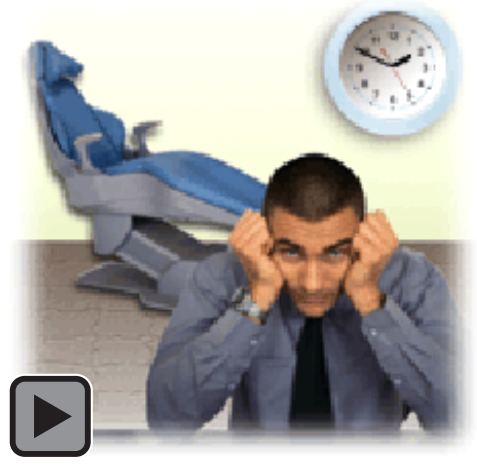

and this lead to the failure of students to complete academic requirements which was very stressful for students as well as the clinical teacher. ${ }^{3}$

The principle aim of this study was to evaluate the prevalence and distribution of broken appointments among third, fourth, and fifth year dental students during one academic year from September 2001 till

May 2002. A secondary aim was to compare patient's compliance between male patients scheduled for treatment at DUC and female patients scheduled at MUC. Distribution of failed appointments in different dental specialities was also observed.

\section{Materials and Methods}

Retrospective information was gathered from the scheduling computers of the dental college during the academic year 2001-2002 (September to May). Data was obtained and patients were categorized according to their appointment behavior as either a booked patient, a treated patient, or as a broken appointment.

productivity and efficiency of a dental care facility. However, this problem is worse in educational dental clinics since dental students rely on patient compliance to meet their treatment and academic goals.

In 1999, Awartani found that $12.24 \%$ of students in periodontal classes at King Saud Dental College had $52.4 \%$ of non compliant patients,

\section{Results}

A total of 19,249 patients were scheduled at MUC; 16,850 patients were treated and 2,399 patients missed their appointments. At DUC, a total of 16,438 patients were scheduled; 13,995 were treated and 2,443 missed their appointments. Descriptive statistics including frequency

Table 1. Patients attendance categorize and the percentage (\%) of broken appointments for both females (MUC) and males (DUC) patients.

\begin{tabular}{|c|c|c|c|c|c|c|c|c|c|c|}
\hline \multirow[b]{2}{*}{ Month } & \multicolumn{4}{|c|}{ MALAZ CAMPUS (MUC) } & \multicolumn{4}{|c|}{ DARRAYAH CAMPUS (DUC) } & \multirow[b]{2}{*}{$x^{2}$} & \multirow[b]{2}{*}{$\stackrel{P}{\text { Value }}$} \\
\hline & $\begin{array}{l}\text { Booked } \\
\text { Patients }\end{array}$ & $\begin{array}{l}\text { Treated } \\
\text { Patients }\end{array}$ & $\begin{array}{l}\text { No.Broken } \\
\text { Appoints. }\end{array}$ & $\begin{array}{l}\% \text { of } \\
\text { Broken } \\
\text { Appts. }\end{array}$ & $\begin{array}{l}\text { Booked } \\
\text { Patients }\end{array}$ & $\begin{array}{l}\text { Treated } \\
\text { Patients }\end{array}$ & $\begin{array}{c}\text { No. } \\
\text { Broken } \\
\text { Appoints }\end{array}$ & $\begin{array}{l}\% \text { of } \\
\text { Broken } \\
\text { Appts. }\end{array}$ & & \\
\hline September & 2159 & 1929 & 230 & $10 \%$ & 2053 & 1673 & 380 & $18.5 \%$ & 52.44 & $4.4^{*}$ \\
\hline October & 3272 & 2959 & 313 & $9.6 \%$ & 2577 & 2203 & 374 & $14.5 \%$ & 34.03 & $5.42^{*}$ \\
\hline November & 2629 & 2238 & 391 & $14.9 \%$ & 1338 & 1150 & 188 & $14.15 \%$ & 0.48 & 0.49 \\
\hline December & 1043 & 853 & 190 & $18 \%$ & 786 & 623 & 163 & $20.7 \%$ & 1.83 & 0.18 \\
\hline January & 1984 & 1721 & 263 & $13.3 \%$ & 2009 & 1661 & 348 & $17.3 \%$ & 12.73 & $3.59^{*}$ \\
\hline February & 1295 & 1139 & 156 & $12.14 \%$ & 1338 & 1150 & 188 & $14.15 \%$ & 2.33 & 0.13 \\
\hline March & 2634 & 2297 & 337 & $12.8 \%$ & 2577 & 2203 & 374 & $14.5 \%$ & 3.27 & 0.07 \\
\hline Aprill & 3125 & 2749 & 376 & $12 \%$ & 2875 & 2506 & 369 & $12.8 \%$ & 0.89 & 0.35 \\
\hline May & 1108 & 965 & 143 & $12.9 \%$ & 885 & 826 & 59 & $6.7 \%$ & 21.03 & $4.52^{\circ}$ \\
\hline TOTAL & 19249 & 16850 & 2399 & $12.4 \%$ & 16438 & 13995 & 2443 & $14.9 \%$ & 43.51 & $4.218^{\circ}$ \\
\hline
\end{tabular}

- Statistically significant $P<0.05$ 
distributions, means, and standard deviations were used. Also, the statistical significance difference between female and male patients' compliance was evaluated using chi square test. Significance was established at $5 \%$ level $(\mathrm{P}<0.05)$.

A summary of patient attendance categories is shown in Table 1. In total, female patients who were appointed at MUC broke $12.4 \%$ of their appointments. Male patients who were appointed at DUC broke $14.9 \%$ of their appointments. This means the males had a significantly higher percentage of failed appointments than females $(p<4.218)$. For both female and male students the highest percentage of broken appointments occurred during the month of December, 2001 which was $18.2 \%$ and $20.7 \%$, respectively. Male patients showed a higher percentage of failed appointments during September, October, and January; female patients showed a higher percentage during the month of May 2002.

Table 2 shows the distribution of missed appointments in relation to different specialties. In male patients, the highest proportion (34\%) of missed appointments was noted in the Restorative Clinic at DUC; in female patients, the highest proportion was found in the Removable Partial Denture Clinic at MUC.

\section{Discussion}

Results showed a high percentage of broken appointments of $12.4 \%$ and $14.9 \%$ for female and male patients, respectively. This is in agreement with Wilson et al. 1984 who stated the number of non compliant patients ranged from $11 \%$ to $45 \%$.
This high percentage is surprising since our dental students provide an appointment reminder by telephone a day before the scheduled visit.

Appointment reminders are a practical way to increase kept appointment rates by patients. ${ }^{5}$ Reminders significantly reduce the broken appointment rate from $9.4 \%$ with no reminder to $3 \%$ with a telephone reminder as mentioned by Reckie and Devlin 1998. ${ }^{1}$ Males had a higher percentage of broken appointments than females. This is in agreement with Demetrion et al. ${ }^{6} 1995$, who found a greater percentage of males less compliant with supportive periodontal treatment. However, it is in disagreement with Gates and Colborn $^{7}$ 1976, Glavind ${ }^{8}$ 1986, Mendoza et al. ${ }^{9}$ 1991, and Checchi et al. ${ }^{10} 1994$ who found no significant relationships between degree of compliance and patient gender.

The current study revealed there is a higher broken appointment rate during the month of December at both MUC and DUC. This may be attributed to the affect of the 10-day long observation of Ramadan by Muslims when working hours are reduced and patients refrain from dental treatments that might unexpectedly break their fast. This issue was highlighted by Raja et al. ${ }^{11} 2000$ who recommended strategies for delivering dental care to Muslim patients during the month of Ramadan .

Table 2. Distribution of missed appointments with the different speciality.

\begin{tabular}{|l|c|c|}
\hline Speciality & Female & Male \\
\hline Restorative & $21 \%$ & $34 \%$ \\
\hline Endodontics & $13 \%$ & $15 \%$ \\
\hline Fixed & $9 \%$ & $9 \%$ \\
\hline Oral Surgery & $6 \%$ & $10 \%$ \\
\hline Removable Partial Denture & $24 \%$ & $10 \%$ \\
\hline Periodontics & $11 \%$ & $11 \%$ \\
\hline Pedodontics & $12 \%$ & $15 \%$ \\
\hline
\end{tabular}


Lastly, males showed a statistically significant higher level of broken appointments during the months of September, October, and January. This may be due to the fact that in Saudi Arabia males are responsible for the transportation of their children. These months are usually the beginning of school days, following vacation periods. This is all in addition to their work responsibility which starts almost at the same time. It could also be due to the less convenient location of DUC which is located on the outskirts of the city versus MUC which is located in the center of the city.

Male clinics showed $34 \%$ of broken appointments occurred in the Restorative Clinic at DUC; female clinics showed $24 \%$ of broken appointments occurred in the Removable Partial Denture Clinic at MUC. This is not easily explained, but it might be related to the day of the appointment. This is in agreement with Morse et al. ${ }^{12} 1984$ who found the highest broken appointment rates were noted for Monday afternoons and evening hours. ${ }^{12}$ However, this study did not investigate reasons for the broken appointments. It should be noted dental treatment is available free-of-charge for all patients treated in the dental college in Saudi Arabia and, therefore, would not be a factor in broken appointments.

\section{Conclusion}

There is a significant difference in the reliability of male and female patients with regard to keeping dental appointments.

The reason for this is unclear and there is a need for further study of this phenomenon. The affect of high rates of broken appointments have significant negative consequences for dental clinic operations of all kinds with a unique academic effect on dental students.

The systematic details of appointment scheduling can be altered to reduce the disruptive effect of the missed appointment. Using strategies such as predictive over-booking with alternative patients based on individual patient characteristics or by simply severing the care relationship with patients who have significant history of repeated broken appointments can be considered. 


\section{References}

1. Reekie D, Devlin H. Preventing failed appointments in general dental practice: a comparison of reminder methods.

Br Dent J. 1998 Nov 14;185(9):472-4.

2. Hashim MJ, Franks P, Fiscella K. Effectiveness of telephone reminders in improving rate of appointments kept at an outpatient clinic: a randomized controlled trial. J Am Board Fam Pract. 2001 MayJun;14(3):193-6.

3. Awartani $\mathrm{F}$. The effect of patient compliance on the students ability to finish their requirement. Cairo Dental J 1999;15(2):881-883.

4. Wilson TG Jr, Glover ME, Schoen J, et. al. T. Compliance with maintenance therapy in a private periodontal practice. J Periodontol. 1984 Aug;55(8):468-73.

5. Irigoyen MM, Findley S, Earle B, et. al. Impact of appointment reminders on vaccination coverage at an urban clinic. Pediatrics. 2000 Oct;106(4 Suppl):919-23.

6. Demetriou N, Tsami-Pandi A, Parashis A. Compliance with supportive periodontal treatment in private periodontal practice. A 14-year retrospective study. J Periodontol. 1995 Feb;66(2):145-9.

7. Gates SJ, Colborn DK. Lowering appointment failures in a neighborhood health center. Med Care. 1976 Mar;14(3):263-7.

8. Glavind $\mathrm{L}$. The result of periodontal treatment in relationship to various background factors. $J$ Clin Periodontol. 1986 Sep;13(8):789-94.

9. Mendoza AR , Newcomb GM, Nixon KC. Compliance with supportive periodontal therapy. J Periodontol. 1991 Dec;62(12):731-6.

10. Checchi L, Pelliccioni GA, Gatto MR, et. al. Patient compliance with maintenance therapy in an Italian periodontal practice. J Clin Periodontol. 1994 May;21(5):309-12.

11. Raja A, Anees K, Bedi R. Transcultural oral health care: 3 . Dental care and treatment during the fast of Ramadan. Dent Update. 2000 Oct;27(8):392-4.

12. Morse DL, Coulter MP, Napodons RJ, et. al. Broken appointments at a neighborhood health center. Emphasis on weather. Med Care. 1984 Sep;22(9):813-7.

\section{About the Author}

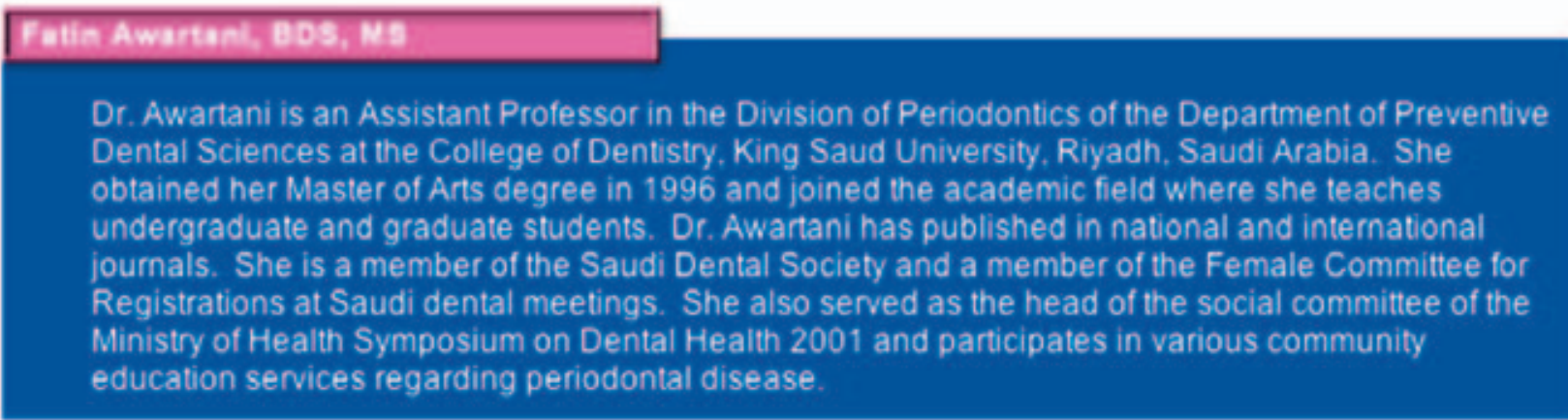

